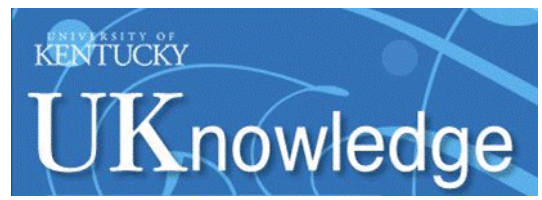

University of Kentucky

UKnowledge

\title{
Toxicity Evaluation of Magnetic Hyperthermia Induced by Remote Actuation of Magnetic Nanoparticles in 3D Micrometastasic Tumor Tissue Analogs for Triple Negative Breast Cancer
}

\author{
Nathanael A. Stocke \\ University of Kentucky, Nas587@gmail.com \\ Pallavi Sethi \\ University of Kentucky, pallavi.sethi@uky.edu \\ Amar Jyoti \\ University of Kentucky, amar.jyoti@uky.edu \\ Ryan Chan \\ University of Kentucky, ryan.chan@uky.edu \\ Susanne M. Arnold \\ University of Kentucky, smarno0@email.uky.edu \\ Follow this and additional works at: https://uknowledge.uky.edu/cme_facpub
}

Part of the Biomaterials Commons, Chemical Engineering Commons, and the Materials Science and See next page for additional authors

Engineering Commons

Right click to open a feedback form in a new tab to let us know how this document benefits you.

\section{Repository Citation}

Stocke, Nathanael A.; Sethi, Pallavi; Jyoti, Amar; Chan, Ryan; Arnold, Susanne M.; Hilt, J. Zach; and Upreti, Meenakshi, "Toxicity Evaluation of Magnetic Hyperthermia Induced by Remote Actuation of Magnetic Nanoparticles in 3D Micrometastasic Tumor Tissue Analogs for Triple Negative Breast Cancer" (2017). Chemical and Materials Engineering Faculty Publications. 59.

https://uknowledge.uky.edu/cme_facpub/59

This Article is brought to you for free and open access by the Chemical and Materials Engineering at UKnowledge. It has been accepted for inclusion in Chemical and Materials Engineering Faculty Publications by an authorized administrator of UKnowledge. For more information, please contact UKnowledge@lsv.uky.edu. 


\section{Toxicity Evaluation of Magnetic Hyperthermia Induced by Remote Actuation of Magnetic Nanoparticles in 3D Micrometastasic Tumor Tissue Analogs for Triple Negative Breast Cancer}

Digital Object Identifier (DOI)

https://doi.org/10.1016/j.biomaterials.2016.12.019

Notes/Citation Information

Published in Biomaterials, v. 120, p. 115-125.

(c) 2016 Elsevier Ltd. All rights reserved.

This manuscript version is made available under the CC-BY-NC-ND 4.0 license https://creativecommons.org/licenses/by-nc-nd/4.0/.

The document available for download is the author's post-peer-review final draft of the article.

\section{Authors}

Nathanael A. Stocke, Pallavi Sethi, Amar Jyoti, Ryan Chan, Susanne M. Arnold, J. Zach Hilt, and Meenakshi Upreti 


\title{
Toxicity evaluation of magnetic hyperthermia induced by remote actuation of magnetic nanoparticles in 3D micrometastasic tumor tissue analogs for triple negative breast cancer
}

\author{
Nathanael A. Stocke ${ }^{\mathrm{a}}$, Pallavi Sethi ${ }^{\mathrm{b}}$, Amar Jyoti ${ }^{\mathrm{b}}$, Ryan Chan ${ }^{\mathrm{b}}$, Susanne M. Arnold ${ }^{\mathrm{c}}, \mathrm{J}$.

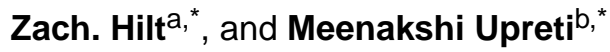 \\ aDepartment of Chemical and Materials Engineering, University of Kentucky, Lexington, KY \\ 40506, USA \\ bDepartment of Pharmaceutical Science, University of Kentucky, Lexington, KY 40506, USA \\ 'College of Medicine, Department of Internal Medicine, University of Kentucky, Lexington, KY \\ 40506, USA
}

\begin{abstract}
Magnetic hyperthermia as a treatment modality is acquiring increased recognition for locoregional therapy of primary and metastatic lung malignancies by pulmonary delivery of magnetic nanoparticles (MNP). The unique characteristic of magnetic nanoparticles to induce localized hyperthermia in the presence of an alternating magnetic field (AMF) allows for preferential killing of cells at the tumor site. In this study we demonstrate the effect of hyperthermia induced by low and high dose of MNP under the influence of an AMF using 3D tumor tissue analogs (TTA) representing the micrometastatic, perfusion independent stage of triple negative breast cancer (TNBC) that infiltrates the lungs. While application of inhalable magnetic nanocomposite microparticles (MnMs) to the micrometastatic TNBC model comprised of TTA generated from cancer and stromal cells, showed no measureable adverse effects in the absence of AMF-exposure, magnetic hyperthermia generated under the influence of an AMF in TTA incubated in a high concentration of MNP $(1 \mathrm{mg} / \mathrm{mL})$ caused significant increase in cellular death/ damage with mechanical disintegration and release of cell debris indicating the potential of these inhalable composites as a promising approach for thermal treatment of diseased lungs. The novelty and significance of this study lies in the development of methods to evaluate in vitro the application of inhalable composites containing MNPs in thermal therapy using a physiologically relevant metastatic TNBC model representative of the microenvironmental characteristics in secondary lung malignancies.
\end{abstract}

Co-corresponding authors:

J. Zach Hilt, Department of Chemical and Materials Engineering, University of Kentucky, 177 F. Paul Anderson Tower. Lexington, KY. 40506-0046, Phone: (859) 257-9844; Fax: (859) 323-1929, zach.hilt@uky.edu

Meenakshi Upreti, Department of Pharmaceutical Sciences, University of Kentucky, 789 S. Limestone St. Lexington, KY. 40536, Phone: (859) 218-1041; Fax: (859) 257-7585, m.upreti@uky.edu

Publisher's Disclaimer: This is a PDF file of an unedited manuscript that has been accepted for publication. As a service to our customers we are providing this early version of the manuscript. The manuscript will undergo copyediting, typesetting, and review of the resulting proof before it is published in its final citable form. Please note that during the production process errors may be discovered which could affect the content, and all legal disclaimers that apply to the journal pertain.

Competing financial interests: The authors declare no competing financial interests. 


\section{Graphical Abstract}

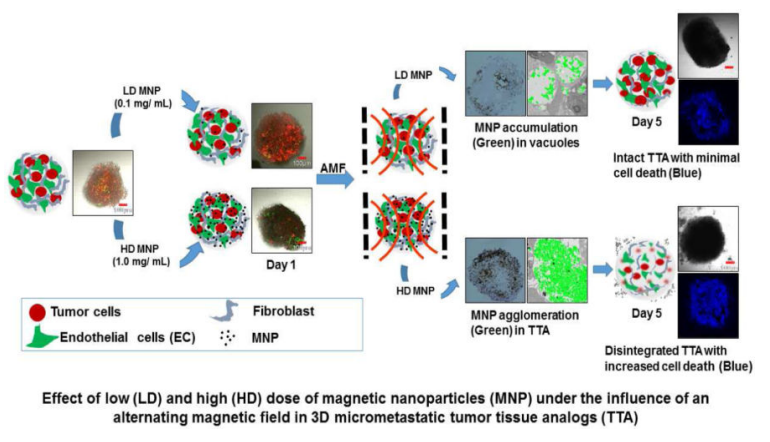

\section{Keywords}

Magnetic nanoparticles (MNP); Tumor tissue analogs (TTA); Alternating magnetic field (AMF); Triple negative breast cancer (TNBC); Metastasis and Transmission electron microscopy (TEM)

\section{Introduction}

Breast cancer is the second leading cause of death in women, surpassed only by lung cancer, where one in every eight women that is diagnosed develops the invasive form of this dreadful malignancy [1]. Triple negative breast cancer (TNBC) is an aggressive subtype of breast cancer wherein the tumor cells do not express the routinely targeted receptors for estrogen (ER), progesterone (PR), and human epidermal growth factor 2 (HER2) [2] and therefore has limited treatment options. Accounting for approximately $20 \%$ of all breast cancers, TNBC has a disproportionately high rate of metastasis [3]. Additionally, patients with distant metastatic disease have a significantly shorter survival time relative to the other breast cancer subtypes [4]. The most common ectopic sites for TNBC to metastasize are the lungs, the liver, bones and the brain [5] with a higher propensity of metastasis to the lungs $[3,6]$. Currently there is an unmet and compelling need for novel approaches to treat patients with metastatic TNBC.

Pulmonary delivery presents a promising approach for local treatment of both primary and secondary lung cancers by facilitating increased drug concentration at the malignant site and reduced systemic side effects [7-9]. Clinical trials with stage IV lung cancer patients have shown a statistically significant increase in median survival time when carboplatin was administered via inhalation combined with injection as opposed to injection only [10]. These results suggest that pulmonary delivery has the potential to complement traditional approaches for patients with metastatic disease in the lungs. Current initiatives employing the delivery of magnetic nanoparticles to the lung is gathering pace for developing novel therapeutic approaches that involve thermal sensitization and/or ablation at the malignant/ metastatic site [11, 12]. Treatment of recurrent TNBC that metastasizes primarily to the lungs aims to improve the quality of life and overall survival. Conventional treatment options are however, not defined and systemically administered, therefore result in increased overall toxicity. Remote actuation of inhalable magnetic nanoparticles to induce magnetic 
hyperthermia at the 4 metastatic lesions of TNBC in the lungs is an attractive concept for management of the malignancy in advanced stages with reduced systemic toxicity.

The biocompatibility and magnetic properties of iron oxide magnetic nanoparticles (MNP) categorizes them in a unique class of materials that have found increasing use in a variety of commercialized biomedical applications $[13,14]$. The ability of magnetic nanoparticles (MNP) and nanocomposites (MnM) to be actuated remotely under the influence of an alternating magnetic field (AMF) has sparked interest in their use for thermal sensitization of cancer cells/ tumors to maximize therapeutic outcomes [15-17]. In the presence of an AMF, iron oxide magnetic nanoparticles generate heat through Brownian and Néel relaxation [18]. The regional hyperthermia so generated is utilized to actuate the onset of therapy or as a form of therapy itself [19-23]. For cancer patients, researchers have been interested in the potential advantages of thermal therapy both in isolation and in combination with anti-cancer agents but the translation to clinical settings of such therapies has been limited [24-28], owing in part due to the inability of existing tumor models to accurately simulate the biological processes and therapeutic response that occur in patients with primary and secondary lung cancer

3D co-culture of different cell types that exist in the tumor and its microenvironment provide a more physiologically relevant representation of in vivo tissue morphology and function. Inclusion of such in vitro tumor models embracing characteristics of the tumor microenvironment for understanding and advancing the parameters for thermoablative therapy will provide more effective treatment options. To this end, our laboratory has developed a 3D co-culture system that incorporates tumor cells, endothelial cells and fibroblasts as color-coded murine tumor tissue analogs (TTA) to better recapitulate the micrometastatic perfusion independent TNBC tumor biology in vitro [29]. The 3D spheroidal co-culture of neoplastic tumor cells with the non-neoplastic stromal components facilitates the formation of a natural extracellular matrix (ECM) allowing for a more accurate recreation of the tumor microenvironment that is often overlooked in in vitro assays.

In the current study, we have devised cost-effective and reproducible in vitro methods using color coded TNBC micrometastatic TTA developed in the laboratory to investigate the potential of inhalable formulations of MNP for secondary lung cancer patients with metastatic TNBC. The murine TNBC micrometastatic TTA are comprised of mCherry fluorescent protein expressing 4T1 tumor cells, the GFP expressing C166 endothelial cells and murine embryonic fibroblasts (MEF) that are grown in in hanging drops of medium without the use of any artificial matrices to a size of $\sim 600 \mu \mathrm{m}$ [30]. The murine $4 \mathrm{~T} 1$ breast carcinoma cell line does not express the ER, PR and HER2 receptors and is therefore representative of the TNBC phenotype [31]. The spray dried MNP are formulated into inhalable magnetic nanocomposites $(\mathrm{MnM})$ [32] before incubating with the TTA. Remote controlled thermal therapy on TTA is accomplished using a custom AMF and the treated tissues are analyzed both quantitatively and qualitatively. 


\section{Material and methods}

\subsection{Cell Lines and Culture}

4T1-mCherry is a red fluorescent protein-expressing murine metastatic mammary carcinoma cell line that closely mimics the triple negative subtype of human breast cancer [33]; was a kind gift from Dr. D. D. Schlaepfer (University of California, San Diego, CA). 2H11, murine tumor endothelial cell line [34], and C166-GFP, a murine green fluorescent proteinexpressing endothelial cell line, were purchased from ATCC (Manassas, VA). Murine embryonic fibroblasts (MEF) were a kind gift from Dr. V. Rangnekar (University of Kentucky, Lexington, KY). The cell lines were routinely cultured in high glucose DMEM containing $10 \%(\mathrm{v} / \mathrm{v})$ fetal bovine serum and $100 \mathrm{IU} / \mathrm{mL}$ penicillin, $100 \mathrm{IU} / \mathrm{mL}$ streptomycin at $37{ }^{\circ} \mathrm{C}, 5 \% \mathrm{CO}_{2}$, and $95 \%$.

\subsection{Chemicals and Reagents}

Iron(II) chloride tetrahydrate ( $\mathrm{FeCl} 2 \cdot 4 \mathrm{H} 2 \mathrm{O})$, iron(III) chloride hexahydrate ( $\mathrm{FeCl} 3 \cdot 6 \mathrm{H} 2 \mathrm{O})$, and d-mannitol were purchased from Sigma-Aldrich (St. Louis, MO). Ammonium hydroxide $(\mathrm{NH} 4 \mathrm{OH})$ was obtained from EMD chemicals (Gibbstown, NJ). Chloroform, anhydrous methanol, and high performance liquid chromatography-grade methanol were purchased from Fisher Scientific (Pittsburgh, PA). Ultrahigh-purity nitrogen gas was purchased from Scott-Gross (Lexington, KY).

\subsection{Formulation and Characterization of MnM and MNP}

Detailed discussion on formulation and characterization of the MnM and MNP is as described in our previous publication[12]. Briefly, magnetic nanocomposite microparticles (MnMs) were formulated by spray drying of iron oxide MNPs and D-mannitol. The physicochemical properties of these MnMs were evaluated and the in vitro aerosol dispersion performance of the dry powders was measured by the Next Generation Impactor ${ }^{\circledR}$. For all powders, the mass median aerosol diameter (MMAD) was $<5 \mu \mathrm{m}$ and deposition patterns revealed that MnMs could deposit throughout the lungs. Heating studies with a custom AMF showed that MNPs retain excellent thermal properties after spray drying into composite dry powders, with specific absorption ratios (SAR) $>200 \mathrm{~W} / \mathrm{g}$.

\subsection{Formation of TNBC micrometastasic TTA}

4T1-mcherry tumor cells, C166-GFP endothelial cells and murine embryonic fibroblasts (MEF) were used to generated 3D BCM tumor tissue analogs in "hanging drops" of media (Dulbecco modified Eagle medium with $10 \%$ fetal bovine serum and antibiotic mix) as previously described [29, 30]. Briefly, the single a cell suspension of 4T1-mcherry cells, C166-GFP cells and MEF cells in equal proportion (3000 cells/20 $\mu \mathrm{L}$ ) was dispensed on the inside of the lid of each well of a 48-well cell culture plate (Greiner Cellstar, Kaysville, UT). The growth of tumor tissue analogs was monitored over time until day 10 in a hanging drop of medium, following which they were subject to MNP (Magnetic nanoparticle) or AMF (Alternating magnetic field) treatment. The tumor tissue analogs were transferred to optically clear repellent plates (Greiner Cellstar, Kaysville, UT) or placed on Millicell culture inserts (Millipore, Billerica, MA) for MNP and AMF treatment respectively. 
Subsequent imaging of TTA and analysis of the treatment response was performed in the repellent plates (Griener, Cellstar, Kaysville, UT).

\subsection{MNP-treatment of TNBC micrometastatic TTA}

The MNP were dispersed in Dulbecco modified Eagle medium with $10 \%$ fetal bovine serum and antibiotic mix at concentrations of $1.0 \mathrm{mg} / \mathrm{mL}$ and $0.1 \mathrm{mg} / \mathrm{mL}$. These two treatment groups will be referred to as high dose (HD) and low dose (LD), respectively. Five microemtastatic TTA in each well of a 96-well plate were incubated in $50 \mathrm{ml}$ of the 0.1 $\mathrm{mg} / \mathrm{mL}$ (LD) and $1.0 \mathrm{mg} / \mathrm{mL}$ (HD) MNP dispersion for 24 hours at $37^{\circ} \mathrm{C}$ in a humidified environment supplemented with $5 \% \mathrm{CO}_{2}$. For the controls fresh medium was added in each well. 20 micrometastatic TTA were analyzed in each treatment group as summarized in Table. 1. Subsequently the TTA were rinsed three times with medium [Dulbecco modified Eagle medium with $10 \%$ fetal bovine serum and antibiotic mix] and placed on a cell culture insert (Millipore, Billerica, MA) within a $35 \mathrm{~mm}$ petri dish (Greiner Cellstar, Kaysville, UT). $2 \mathrm{ml}$ of medium was added the dish to ensure sufficient supply of nutrients and a solidair interface for the TTA during hyperthermia treatments.

\subsection{Remotely actuated hyperthermia using a custom alternating magnetic field (AMF)}

For hyperthermia experiments each $35 \mathrm{~mm}$ petri dish with the TNBC micrometastatic TTA lodged on the cell culture insert, was placed directly above the coil of a custom Taylor Winfield ${ }^{\circledR}$ Alternating Magnetic Field (AMF) Source (Youngstown, OH). The AMF was run at a field strength of $55 \mathrm{kA} / \mathrm{m}$ and a frequency of $300 \mathrm{kHz}$. The treatment groups were exposed to the AMF field for 1 hour. During the experiments a custom built Styrofoam casing was used to enclose the coil and petri dish and a hot air supply was used to maintain the temperature of the surroundings to approximately $37^{\circ} \mathrm{C}$. A Luxtron fiber Optic Thermometer (LumaSense Technologies, Santa Clara, CA) was used to measure the temperature of the surroundings throughout the experiments. The hot air supply was adjusted manually in order to maintain the surrounding temperature to $37^{\circ} \mathrm{C}$. After AMFexposure, each treatment group was allowed to incubate for 4 hours at $37^{\circ} \mathrm{C}$ in a humidified environment supplemented with $5 \% \mathrm{CO}_{2}$. The $\mathrm{BCM}$ tumor tissue analogs were then fixed in $4 \%$ formaldehyde for $24 \mathrm{hrs}$. Table 1 summarizes the treatment groups in this study and the corresponding naming convention used here.

\subsection{Fluorescent imaging on micrometastatic tumor tissue analogs}

After being subject to remotely actuated hyperthermia the BCM tumor tissue analogs ( $n=5$ / treatment group) were incubated for 72 hours at $37^{\circ} \mathrm{C}$ in a humidified environment supplemented with 5\% $\mathrm{CO}_{2}$ and imaged with a FV1000 laser scanning confocal microscope. Images were processed using FV10-ASW 1.7 viewer software. Images were analyzed using Olympus image analysis software and ImageJ 1.47v (NIH, Bethesda, USA) as 8-bit monochromatic image files. Accumulation of Sytox blue staining, mCherry- and GFPexpressing cells was imaged using argon lasers at $406 \mathrm{~nm}, 532$ and $453 \mathrm{~nm}$, respectively. Bright field images were captured to estimate the size of the micrometastatic TTA. 


\subsection{Quantification of cell death using Sytox Blue}

In order to quantify the amount of cell death five BCM tumor tissue analogs per treatment group were stained with Sytox Blue ( $\mathrm{n}=5$ /group). The SYTOX blue stain (Molecular Probes, Inc, Eugene, OR) is a high-affinity nucleic acid stain that easily penetrates cells with compromised plasma membranes and can be excited with argon 406 lasers, making it a useful indicator of dead cells within a population.

\subsection{Prussian blue staining and imaging of iron uptake}

The amount of iron present in TNBC micrometastatic TTA was evaluated using a Prussian Blue stain for iron content. TTA were harvested and processed through sucrose gradient and then snap frozen in O.C.T, Tissue-Tek, Miles USA, Inc. (Elkhart, IN). Five micrometer cryostat sections were obtained with the help of a Leica CM1950 cryotome and transferred on to Superfrost ${ }^{\mathrm{TM}}$ Plus slides (Fischer Scientific; Boston, MA) for detection of iron-oxide particles using Prussian blue staining. Slides were incubated in freshly prepared 10\% aqueous solution of potassium ferrocyanide and hydrochloric acid for 20 minutes, washed three times with distilled water and counterstained with nuclear red for 5 minutes. After rinsing the slides, sections were dehydrated through grades of alcohol and then cleared with xylene and permanently mounted with permount media (Sigma) and coverslip. Light

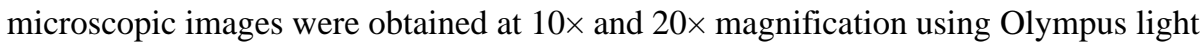
microscope (Olympus America Inc., Melville, NY).

\subsection{Transmission electron microscopy (TEM) for intra-structural changes in TTA post- treatment}

Transmission electron microscopy (TEM) was carried out on TM analogs ( $\mathrm{n}=5$ ) in order to qualitatively observe MNP uptake and cellular characteristics after AMF treatment. Immediately following 1 hour of AMF exposure the TTA were placed in an incubator for 4 hours at $37^{\circ} \mathrm{C}$ in a humidified environment supplemented with $5 \% \mathrm{CO}_{2}$. Subsequently, TTA were transferred to a $20 \mathrm{~mL}$ glass vial and washed with 0.1 M Sorenson's Phosphate Buffer (SPB) to remove media before fixing. The buffer was removed and a $3.5 \%$ glutaraldehyde solution in $0.1 \mathrm{M}$ SPB was added to the vial and allowed to sit for $45 \mathrm{~min}$ at approximately $4^{\circ} \mathrm{C}$. Subsequently, the fixate was removed and the TTA were washed three times for 5 minutes in $0.1 \mathrm{M}$ SPB supplemented with 5\% sucrose. After this, the SBS was removed and a $1 \%$ osmium tetroxide solution in $0.1 \mathrm{M} \mathrm{SPB}$ was added to the vial containing the TTA and allowed to sit for $45 \mathrm{mins}$ at $4{ }^{\circ} \mathrm{C}$. The osmium tetroxide solution was removed and TTA were washed with $0.1 \mathrm{M} \mathrm{SPB}$ and dehydrated by subsequent ethanol washes at 50-, 70-, 80-, 90-, and 100\% (twice) for 10 mins each. After the second wash with $100 \%$ ethanol the TTA were washed with propylene oxide twice for 20 mins each. The propylene oxide was then removed and the TTA were allowed to sit overnight under a mild heating lamp in a 1:1 mixture of propylene oxide and an epoxy resin. The next day, the propylene oxide and epoxy resin mixture was removed and the cells were washed with just the epoxy resin twice for an hour each time. After the second wash was removed the TTA were transferred to a centrifuge tube for sectioning, epoxy resin was added and the samples were allowed to polymerize for 48 hours at $60^{\circ} \mathrm{C}$. After polymerization, the pellets were sliced into 70-90 $\mu \mathrm{m}$ sections with a Reichert-Jung Ultracut E microtome and stained with a combination of 
uranyl acetate, (saturated solution in 70\% ethanol) for 5 minutes, and lead citrate, for 2 minutes. The specimens were observed using a Philips Tecnai Biotwin 12, manufactured by FEI.

\subsection{Image processing and analysis}

Images of cell vacuolization and nanoparticle aggregation were manually colored and processed using Adobe Photoshop CS6 (Adobe Systems Inc., San Jose, CA). Colored regions were extracted from the original image with the use of Adobe Photoshop CS6. Area analysis of the colored regions was conducted with the use of ImageJ, v1.47 (National Institutes of Health, Bethesda, MD).

\subsection{Statistical Analysis}

Data are expressed as mean $\pm 1 \mathrm{SD}$ of at least three different experiments. Statistical significance of difference in means was performed using parametric two sample $t$ test with unequal variance $(a=0.05$; GraphPad Prism).

\section{Results and Discussion}

\subsection{Increasing exposure to iron oxide MNP masks the fluorescence intensity of color coded cell types in TTA}

The effect of MNPs, released from the inhalable dry composites, on the micrometastatic TTA $(n=5)$ was examined 5 days post MNP-exposure with fluorescent confocal and differential contrast interference (DIC) microscopy for three different MNP doses namely control, $\mathrm{LD}(0.1 \mathrm{mg} / \mathrm{mL})$, and $\mathrm{HD}(1 \mathrm{mg} / \mathrm{mL})$. The increasing concentration of MNP exposure masked the fluorescence intensity of different cell types comprised in the TTA upon incubation with increasing MNP concentration (Fig. 1). The incubation with increasing concentrations of MNP is expected to cause higher levels of MNP deposition on TTA resulting in dark areas where the nanoparticles diffract light and obscure fluorescence of color coded cell types in the multicellular TTA. This is a common issue with in vitro fluorescent assays using MNPs and must be taken in consideration when analyzing the data.

In addition to illustrating the reproducibility, the data shows no apparent adverse effect on the mechanical stability of the TTA upon exposure with MNP alone and confirms the multicellular composition evidenced by the presence of all three cell types namely, the MEF (colorless), 4T1 (red) and C166 (green) cells in the TTA.

\subsection{AMF exposure causes mechanical deterioration in TTA incubated with increasing concentration of MNP}

The effect of AMF-exposure on TTA with and without incubation with MNP was also examined using fluorescent and bright field (DIC) microscopy. TTA from each treatment group $(n=5)$ were placed in an AMF for 1 hour (designated +AMF) that were compared with their corresponding TTA incubated with the same MNP dose but not placed in AMF (designated -AMF). While no difference was observed in the-AMF and +AMF control groups that were not incubated with MNP, mechanical deterioration was noticed in the TTA incubated with MNP. Increasing mechanical breakdown after AMF exposure was evidenced 
by occurrence of cellular debris surrounding TTA incubated in higher concentration of MNP (Fig. 2). This effect was increasingly pronounced in the HD MNP+AMF treatment group wherein large amounts of cellular debris were observed (Fig 2).

\subsection{Increased cellular damage and MNP accumulation in TTA exposed to high dose of MNP remotely actuated via an AMF}

Cellular damage by magnetic hyperthermia from MNP subject to AMF exposure was quantified in the in vitro micrometastatic TNBC model using TTA to examine the potential of the inhalable composites for treatment of secondary lung malignancies. The extent of cellular damage was assessed by quantification of SYTOX ${ }^{\circledR}$ Blue uptake in the TTA from each treatment group $(n=5)$. Sytox blue is a fluorescent nuclear counterstain impermeant to live cells and a useful indicator of cell death and damage. Fluorescent images captured at $480 \mathrm{~nm}$ revealed higher staining for SYTOX ${ }^{\circledR}$ Blue in TTA incubated in increasing concentration of MNP and AMF exposure for $1 \mathrm{hr}$ (Fig. 3A).

The normalized mean integrated fluorescence intensity of the SYTOX ${ }^{\circledR}$ Blue in TTA from each treatment group was calculated. The graphical representation of the quantitative data (Fig. 3B) showed comparable levels of cell death/damage in all treatment groups without AMF exposure (-AMF), but an increase in cell death / damage in both the low and high dose MNP treatment groups of TTA that were subject to magnetic hyperthermia induced by an AMF for $1 \mathrm{hr}$ (LD MNP + AMF and HD MNP +AMF) (Fig 3B). Furthermore, despite the potential reduction in the fluorescent intensity of color coded cell types in the TTA subject to treatment with high dose MNP and AMF exposure (HD MNP+AMF) as described in Fig. 1 , a statistically significant increase $(\mathrm{p}<0.05)$ in cell death/ damage was observed only in this treatment group. Control groups with and without AMF exposure did not show any notable increase in SYTOX ${ }^{\circledR}$ Blue intensity.

\subsection{Magnetic hyperthermia induced via an AMF increases the MNP uptake in TTA}

To investigate the accumulation and agglomeration of the MNPs in the TTA, histological sections were cut and stained with Prussian blue for iron content. As evidenced from the images there was higher amount of iron in the TTA incubated at a higher dose (HD) of MNP (Fig. 4). Interestingly, this increase in iron accumulation with HD MNP treatment was much more uniform in the TTA that were subject to AMF exposure for $1 \mathrm{hr}$. Iron accumulation in TTA subject to HD MNP treatment only was restricted to the peripheral TTA layers. Images of TTA not treated with MNP (Control) with or with exposure to AMF did not exhibit any changes (Fig. 4).

\subsection{TEM elucidates varying patterns of iron uptake in TTA exposed to low and high dose of MNP with magnetic hyperthermia induced via an AMF}

To gain better insights into the MNP-localization and cellular response post AMF exposure, the TTA were cast in resin, sectioned, and stained for TEM imaging. Electron micrographs acquired from the interior and exterior regions of the TTA incubated in low and high dose of MNP with AMF exposure revealed different patterns of iron uptake in the two treatment groups (LD MNP +AMF and HD MNP+AMF) (Fig. 5). 
TEM images from the center (interior) of the TTA showed some accumulation of MNP within cell vacuoles and comparable uptake in intercellular spaces or vacuoles in the periphery (exterior) of the TTA at 5 days' post treatment with LD+AMF (Fig. 6A). The HD + AMF treatment of TTA however, displayed the bulk of MNP agglomerates accumulated in the interior with marginal acquisition in the exterior of the TTA. Quantitative analysis of MNP accumulation further confirms higher accumulation of MNP in the interior of TTA upon treatment with higher dose of MNP in comparison to the lower dose of MNP when accompanied with magnetic hyperthermia induced using AMF (Fig. 6B \& C). The MNPs that are released from the composite powders have a core diameter of approximately $10 \mathrm{~nm}$ and a hydrodynamic diameter of approximately $150 \mathrm{~nm}$ [12] during exposure to the TTA; however, a large portion of the MNP that accumulate in TTA appear as very large agglomerates. A possible explanation could be owing to the deposition of MNP on the surface of TTA during the $24 \mathrm{hr}$ incubation period.

\subsection{TEM images indicate vacuolization and extracellular deposition in TTA when exposed to magnetic hyperthermia induced via remote actuation of MNP by an AMF}

Conditions including magnetic hyperthermia that cause cellular stress may induce multiple distinct types of tumor cell death, such as: apoptosis, necrosis and autophagy, occurring concurrently or successively [35-39]. In addition, heat-generating magnetic nanocubes have demonstrated the potential to 'destructure' the extracellular matrix in the tumor stroma and improve nanoparticle / drug penetration at the tumor site [40]. In this study we are also able to observe morphologic features of autophagy such as accumulation of extracellular debris and vacuolization in TTA subject to MNP exposure with AMF (Fig. 7) [41].

While the vacuolization (red arrows) was much more prevalent in TTA treated with low dose of MNP with AMF (LD MNP+AMF), the nanoparticle agglomerates within cells (Blue outline) and extracellular deposition (yellow arrows) was notably higher in TTA exposed to high dose MNP and AMF exposure (HD MNP+AMF) (Fig. 7)

Increasing magnification of the electron photomicrographs elucidated upon engulfment of small amounts of MNP in TTA treated with LD MNP+AMF (Fig. 8, middle and lower panel). This phenomenon of cytoplasmic vacuolization and precipitation of extracellular debris indicating autophagy was not observed in TTA that were subject to AMF exposure alone (Control+AMF) (Fig. 8, top panel). A quantitative analysis for vacuolization of the cytoplasm in TTA post treatment from TEM images further confirmed their formation as a consequence of low dose MNP exposure with an AMF (Fig. 9, middle panel). While large agglomerates of MNP were formed in TTA upon exposure to high dose of MNP subject to an AMF (Fig. 9, lower panel), no significant vacuolization was observed upon quantitation (Fig. 9B, C). The phenomenon of cytoplasmic vacuolization was also not observed in treatment groups not exposed to an AMF and Control groups that were not incubated with MNP.

Efforts are underway to standardize more powerful techniques such as second harmonic generation microscopy to analyze alterations in extracellular matrix proteins (collagen), confocal and immunohistochemistry of TTA microarrays to delineate the role of different cell types contributing to the tumor response in vivo. 


\section{Conclusions}

AMF-assisted forced oscillations of magnetic nanoparticles (MNP) The effectiveness of magnetic hyperthermia has been demonstrated using aerosolized nanocomposites as inhalable super paramagnetic iron oxide (SPIO) nanoparticles in an orthotopic lung cancer mouse model where a significant reduction in micrometastatic-NSCLC tumor growth was observed with exposure to an AMF [42]. Others have reported the ability to target liquid aerosols containing MNPs to specific regions within the lungs of mice by application of a stationary magnetic field $[43,44]$. Such findings illustrate the potential of these MNPcontaining inhalable aerosols for treatment of patients with primary or metastatic lung cancer where surgery is not recommended [45]. Preclinical animal investigations of inhaled therapeutics in lung malignancies however, depend on complicated intratracheal and intranasal routes monitored in appropriate animal models requiring a significantly large sample size. Therefore, to decipher the intracellular events triggered by magnetic hyperthermia and standardize the optimal dose by titration of MNP concentration with the duration of AMF exposure, it is imperative to develop in vitro tumor models that are able to recapitulate the microenvironmental aspects of the lung malignancy and allow high throughput screening in a cost-effective and reproducible manner. Controlled experimental manipulations in vitro settings present an extremely useful predictive tool for optimization of dosing schedules before translation of data to animals and clinical trials [46]. The TNBC micrometastasic tumor tissue analogs (TTA) developed in our laboratory have demonstrated a consistent size, tissue-like morphology, natural extracellular matrix and presence of markers representative of the tumor tissue [30], thereby highlighting their potential as advanced in vitro models for understanding treatment response in secondary lung malignancies. The experimental design for induction of magnetic hyperthermia in the present study with the TTA laid on transwell inserts mounted on petri dishes containing media recreated the air-liquid interface as observed in primary lung cancer and ectopic lung metastasis such as TNBC. Application of inhalable magnetic nanocomposite microparticles $(\mathrm{MnM})$ to the micrometastatic TNBC model (TTA) showed no measureable adverse effects in the absence of AMF-exposure. However, hyperthermia induced via an alternating magnetic field in TTA subjected to a high concentration of MNP $(1 \mathrm{mg} / \mathrm{mL})$ showed statistically significant increase in cellular death with higher accumulation of MNP, indicating the potential of these inhalable composites for future development of thermal therapy. Additional morphological changes evidenced as a consequence of hyperthermia induced by remote actuation of MNP under an AMF in the TTA, were mechanical deterioration that was demonstrated by confocal microscopy and vacuolization with extracellular deposition observed in the TEM images of the TTA. While we are still in the process of developing novel strategies to investigate the multiple effects of magnetic hyperthermia such as apoptosis, necrosis and autophagy in conjunction with the standardization of MNP distribution in our 3D micrometastatic tumor model, the TTA used in this study provide a physiologically relevant in vitro model of secondary lung malignancies from metastatic TNBC and our findings suggest the potential of inhalable composites containing MNP for inducing locoregional hyperthermia in primary and secondary lung cancer. While AMF-assisted thermal therapy has received global attention, recent reports suggest that forced oscillation of MNP via low power and low frequency AMF 
(35 kHz) result in direct mechanical damage of cancer cells without causing any thermal injury [47-49]. We expect the 3D microemetastatic model as an ideal test-bed or platform for comparison of the direct effects of MNP oscillations via low frequency AMF with the indirect thermal effects induced by high frequency AMF and development of biomedical applications for MNP in cancer therapy.

\section{Acknowledgments}

NAS and AJ were supported by the R25CA153954 from the NCI. Additional support for the study was provided by the R21CA173609 (MU) also from the NCI. The content is solely the responsibility of the authors and does not necessarily represent the official views of the National Cancer Institute or the National Institutes of Health.

\section{References}

1. DeSantis C, Ma JM, Bryan L, Jemal A. Breast Cancer Statistics, 2013. Ca-a Cancer Journal for Clinicians. 2014; 64(1):52-62. [PubMed: 24114568]

2. Hudis CA, Gianni L. Triple-Negative Breast Cancer: An Unmet Medical Need. Oncologist. 2011; 16:1-11.

3. Andre F, Zielinski CC. Optimal strategies for the treatment of metastatic triple-negative breast cancer with currently approved agents. Annals of Oncology. 2012; 23:46-51. [PubMed: 21464158]

4. Kassam F, Enright K, Dent R, Dranitsaris G, Myers J, Flynn C, Fralick M, Kumar R, Clemons M. Survival Outcomes for Patients with Metastatic Triple-Negative Breast Cancer: Implications for Clinical Practice and Trial Design. Clinical Breast Cancer. 2009; 9(1):29-33. [PubMed: 19299237]

5. Tseng LM, Hsu NC, Chen SC, Lu YS, Lin CH, Chang DY, Li H, Lin YC, Chang HK, Chao TC, Ouyang F, Hou MF. Distant metastasis in triple-negative breast cancer. Neoplasma. 2013; 60(3): 290-294. [PubMed: 23373998]

6. Gerratana L, Fanotto V, Bonotto M, Bolzonello S, Minisini AM, Fasola G, Puglisi F. Pattern of metastasis and outcome in patients with breast cancer. Clinical \& Experimental Metastasis. 2015; 32(2):125-133. [PubMed: 25630269]

7. Otterson GA, Villalona-Calero MA, Sharma S, Kris MG, Imondi A, Gerber M, White DA, Ratain MJ, Schiller JH, Sandler A, Kraut M, Mani S, Murren JR. Phase I study of inhaled doxorubicin for patients with metastatic tumors to the lungs. Clinical Cancer Research. 2007; 13(4):1246-1252. [PubMed: 17317836]

8. Otterson GA, Villalona-Calero MA, Hicks W, Pan XL, Ellerton JA, Gettinger SN, Murren JR. Phase I/II Study of Inhaled Doxorubicin Combined with Platinum-Based Therapy for Advanced NonSmall Cell Lung Cancer. Clinical Cancer Research. 2010; 16(8):2466-2473. [PubMed: 20371682]

9. Kuzmov A, Minko T. Nanotechnology approaches for inhalation treatment of lung diseases. J Control Release. 2015; 219:500-518. [PubMed: 26297206]

10. Zarogoulidis P, Eleftheriadou E, Sapardanis I, Zarogoulidou V, Lithoxopoulou H, Kontakiotis T, Karamanos N, Zachariadis G, Mabroudi M, Zisimopoulos A, Zarogoulidis K. Feasibility and effectiveness of inhaled carboplatin in NSCLC patients. Investigational New Drugs. 2012; 30(4): 1628-1640. [PubMed: 21739158]

11. Shenoi MM, Shah NB, Griffin RJ, Vercellotti GM, Bischof JC. Nanoparticle preconditioning for enhanced thermal therapies in cancer. Nanomedicine (Lond). 2011; 6(3):545-563. [PubMed: 21542691]

12. Stocke NA, Meenach SA, Arnold SM, Mansour HM, Hilt JZ. Formulation and characterization of inhalable magnetic nanocomposite microparticles (MnMs) for targeted pulmonary delivery via spray drying. Int J Pharm. 2015; 479(2):320-328. [PubMed: 25542988]

13. Hao R, Xing RJ, Xu ZC, Hou YL, Gao S, Sun SH. Synthesis, Functionalization, and Biomedical Applications of Multifunctional Magnetic Nanoparticles. Advanced Materials. 2010; 22(25):27292742. [PubMed: 20473985] 
14. Mahmoudi M, Sant S, Wang B, Laurent S, Sen T. Superparamagnetic iron oxide nanoparticles (SPIONs): Development, surface modification and applications in chemotherapy. Advanced Drug Delivery Reviews. 2011; 63(1-2):24-46. [PubMed: 20685224]

15. Jordan A, Scholz R, Wust P, Fahling H, Felix R. Magnetic fluid hyperthermia (MFH): Cancer treatment with $\mathrm{AC}$ magnetic field induced excitation of biocompatible superparamagnetic nanoparticles. Journal of Magnetism and Magnetic Materials. 1999; 201:413-419.

16. Frimpong RA, Hilt JZ. Magnetic nanoparticles in biomedicine: synthesis, functionalization and applications. Nanomedicine. 2010; 5(9):1401-1414. [PubMed: 21128722]

17. Hauser AK, Wydra RJ, Stocke NA, Anderson KW, Hilt JZ. Magnetic nanoparticles and nanocomposites for remote controlled therapies. J Control Release. 2015; 219:76-94. [PubMed: 26407670]

18. Torres-Lugo M, Rinaldi C. Thermal potentiation of chemotherapy by magnetic nanoparticles. Nanomedicine (Lond). 2013; 8(10):1689-1707. [PubMed: 24074390]

19. Satarkar NS, Hilt JZ. Hydrogel nanocomposites as remote-controlled biomaterials. Acta Biomaterialia. 2008; 4(1):11-16. [PubMed: 17855176]

20. Satarkar NS, Hilt JZ. Magnetic hydrogel nanocomposites for remote controlled pulsatile drug release. Journal of Controlled Release. 2008; 130(3):246-251. [PubMed: 18606201]

21. Frimpong RA, Dou J, Pechan M, Hilt JZ. Enhancing remote controlled heating characteristics in hydrophilic magnetite nanoparticles via facile co-precipitation. Journal of Magnetism and Magnetic Materials. 2010; 322(3):326-331.

22. Satarkar NS, Meenach SA, Anderson KW, Hilt JZ. Remote Actuation of Hydrogel Nanocomposites: Heating Analysis. Modeling, and Simulations, Aiche Journal. 2011; 57(4):852860.

23. Wydra RJ, Kruse AM, Bae Y, Anderson KW, Hilt JZ. Synthesis and characterization of PEG-iron oxide core-shell composite nanoparticles for thermal therapy. Materials Science \& Engineering CMaterials for Biological Applications. 2013; 33(8):4660-4666.

24. Kruse AM, Meenach SA, Anderson KW, Hilt JZ. Synthesis and characterization of CREKAconjugated iron oxide nanoparticles for hyperthermia applications. Acta Biomaterialia. 2014; 10(6):2622-2629. [PubMed: 24486913]

25. Babincova M, Altanerova V, Altaner C, Bergemann C, Babinec P. In vitro analysis of cisplatin functionalized magnetic nanoparticles in combined cancer chemotherapy and electromagnetic hyperthermia. Ieee Transactions on Nanobioscience. 2008; 7(1):15-19. [PubMed: 18334449]

26. Thiesen B, Jordan A. Clinical applications of magnetic nanoparticles for hyperthermia. International Journal of Hyperthermia. 2008; 24(6):467-474. [PubMed: 18608593]

27. Lubner MG, Brace CL, Hinshaw JL, Lee FT. Microwave Tumor Ablation: Mechanism of Action, Clinical Results, and Devices. Journal of Vascular and Interventional Radiology. 2010; 21(8):S192-S203. [PubMed: 20656229]

28. Vertrees RA, Leeth A, Girouard M, Roach JD, Zwischenberger JB. Whole-body hyperthermia: a review of theory, design and application. Perfusion-Uk. 2002; 17(4):279-290.

29. Upreti M, Jamshidi-Parsian A, Koonce NA, Webber JS, Sharma SK, Asea AA, Mader MJ, Griffin RJ. Tumor-Endothelial Cell Three-dimensional Spheroids: New Aspects to Enhance Radiation and Drug Therapeutics. Transl. Oncol. 2011; 4(6):365-376. [PubMed: 22191001]

30. Sethi P, Jyoti A, Swindell EP, Chan R, Langner UW, Feddock JM, Nagarajan R, O'Halloran TV, Upreti M. 3D tumor tissue analogs and their orthotopic implants for understanding tumor-targeting of microenvironment-responsive nanosized chemotherapy and radiation. Nanomedicine. 2015; 11(8):2013-2023. [PubMed: 26282381]

31. Kau P, Nagaraja GM, Zheng H, Gizachew D, Galukande M, Krishnan S, Asea A. A mouse model for triple-negative breast cancer tumor-initiating cells (TNBC-TICs) exhibits similar aggressive phenotype to the human disease. Bmc Cancer. 2012; 12

32. Stocke NA, Meenach SA, Arnold SM, Mansour HM, Hilt JZ. Formulation and characterization of inhalable magnetic nanocomposite microparticles (MnMs) for targeted pulmonary delivery via spray drying. Int J Pharm. 2014; 479(2):320-328. [PubMed: 25542988]

33. Mitra SK, Lim ST, Chi A, Schlaepfer DD. Intrinsic focal adhesion kinase activity controls orthotopic breast carcinoma metastasis via the regulation of urokinase plasminogen activator 
expression in a syngeneic tumor model. Oncogene. 2006; 25(32):4429-4440. [PubMed: 16547501]

34. Walter-Yohrling J, Morgenbesser S, Rouleau C, Bagley R, Callahan M, Weber W, Teicher BA. Murine endothelial cell lines as models of tumor endothelial cells. Clin Cancer Res. 2004; 10(6): 2179-2189. [PubMed: 15041739]

35. Kobayashi T, Kakimi K, Nakayama E, Jimbow K. Antitumor immunity by magnetic nanoparticlemediated hyperthermia. Nanomedicine (Lond). 2014; 9(11):1715-1726. [PubMed: 25321171]

36. Oh Y, Lee N, Kang HW, Oh J. In vitro study on apoptotic cell death by effective magnetic hyperthermia with chitosan-coated $\mathrm{MnFe}(2) \mathrm{O}(4)$. Nanotechnology. 2016; 27(11):115101. [PubMed: 26871973]

37. Blanco-Andujar C, Ortega D, Southern P, Nesbitt SA, Thanh NT, Pankhurst QA. Real-time tracking of delayed-onset cellular apoptosis induced by intracellular magnetic hyperthermia. Nanomedicine (Lond). 2016; 11(2):121-136. [PubMed: 26654549]

38. Shetake NG, Kumar A, Gaikwad S, Ray P, Desai S, Ningthoujam RS, Vatsa RK, Pandey BN. Magnetic nanoparticle-mediated hyperthermia therapy induces tumour growth inhibition by apoptosis and Hsp90/AKT modulation. Int J Hyperthermia. 2015; 31(8):909-919. [PubMed: 26416812]

39. Sadhukha T, Wiedmann TS, Panyam J. Enhancing therapeutic efficacy through designed aggregation of nanoparticles. Biomaterials. 2014; 35(27):7860-7869. [PubMed: 24947232]

40. Kolosnjaj-Tabi J, Di Corato R, Lartigue L, Marangon I, Guardia P, Silva AK, Luciani N, Clement O, Flaud P, Singh JV, Decuzzi P, Pellegrino T, Wilhelm C, Gazeau F. Heat-generating iron oxide nanocubes: subtle "destructurators" of the tumoral microenvironment. ACS Nano. 2014; 8(5): 4268-4283. [PubMed: 24738788]

41. Galluzzi L, Maiuri MC, Vitale I, Zischka H, Castedo M, Zitvogel L, Kroemer G. Cell death modalities: classification and pathophysiological implications. Cell Death Differ. 2007; 14(7): 1237-1243. [PubMed: 17431418]

42. Sadhukha T, Wiedmann TS, Panyam J. Inhalable magnetic nanoparticles for targeted hyperthermia in lung cancer therapy. Biomaterials. 2013; 34(21):5163-5171. [PubMed: 23591395]

43. Hasenpusch G, Geiger J, Wagner K, Mykhaylyk O, Wiekhorst F, Trahms L, Heidsieck A, Gleich B, Bergemann C, Aneja MK, Rudolph C. Magnetized Aerosols Comprising Superparamagnetic Iron Oxide Nanoparticles Improve Targeted Drug and Gene Delivery to the Lung. Pharmaceutical Research. 2012; 29(5):1308-1318. [PubMed: 22271050]

44. Dames P, Gleich B, Flemmer A, Hajek K, Seidl N, Wiekhorst F, Eberbeck D, Bittmann I, Bergemann C, Weyh T, Trahms L, Rosenecker J, Rudolph C. Targeted delivery of magnetic aerosol droplets to the lung. Nature Nanotechnology. 2007; 2(8):495-499.

45. Zarogoulidis K, Zarogoulidis P, Darwiche K, Boutsikou E, Machairiotis N, Tsakiridis K, Katsikogiannis N, Kougioumtzi I, Karapantzos I, Huang HD, Spyratos D. Treatment of non-small cell lung cancer (NSCLC). Journal of Thoracic Disease. 2013; 5:S389-S396. [PubMed: 24102012]

46. Kirstein MN, Brundage RC, Moore MM, Williams BW, Hillman LA, Dagit JW, Fisher JE, Marker $\mathrm{PH}$, Kratzke RA, Yee D. Pharmacodynamic characterization of gemcitabine cytotoxicity in an in vitro cell culture bioreactor system. Cancer Chemother Pharmacol. 2008; 61(2):291-299. [PubMed: 17429628]

47. Carrey J, Connord V, Respaud M. Ultrasound generation and high-frequency motion of magnetic nanoparticles in an alternating magnetic field: Toward intracellular ultrasound therapy? Applied Physics Letters. 2013; 102(23):232404.

48. Cheng D, Li X, Zhang G, Shi H. Morphological effect of oscillating magnetic nanoparticles in killing tumor cells. Nanoscale Res Lett. 2014; 9(1):195. [PubMed: 24872797]

49. Calatayud MP, Asin L, Tres A, Goya GF, Ibarra MR. Cell Bystander Effect Induced by Radiofrequency Electromagnetic Fields and Magnetic Nanoparticles. Current Nanoscience. 2016; 12(3):372-377. 


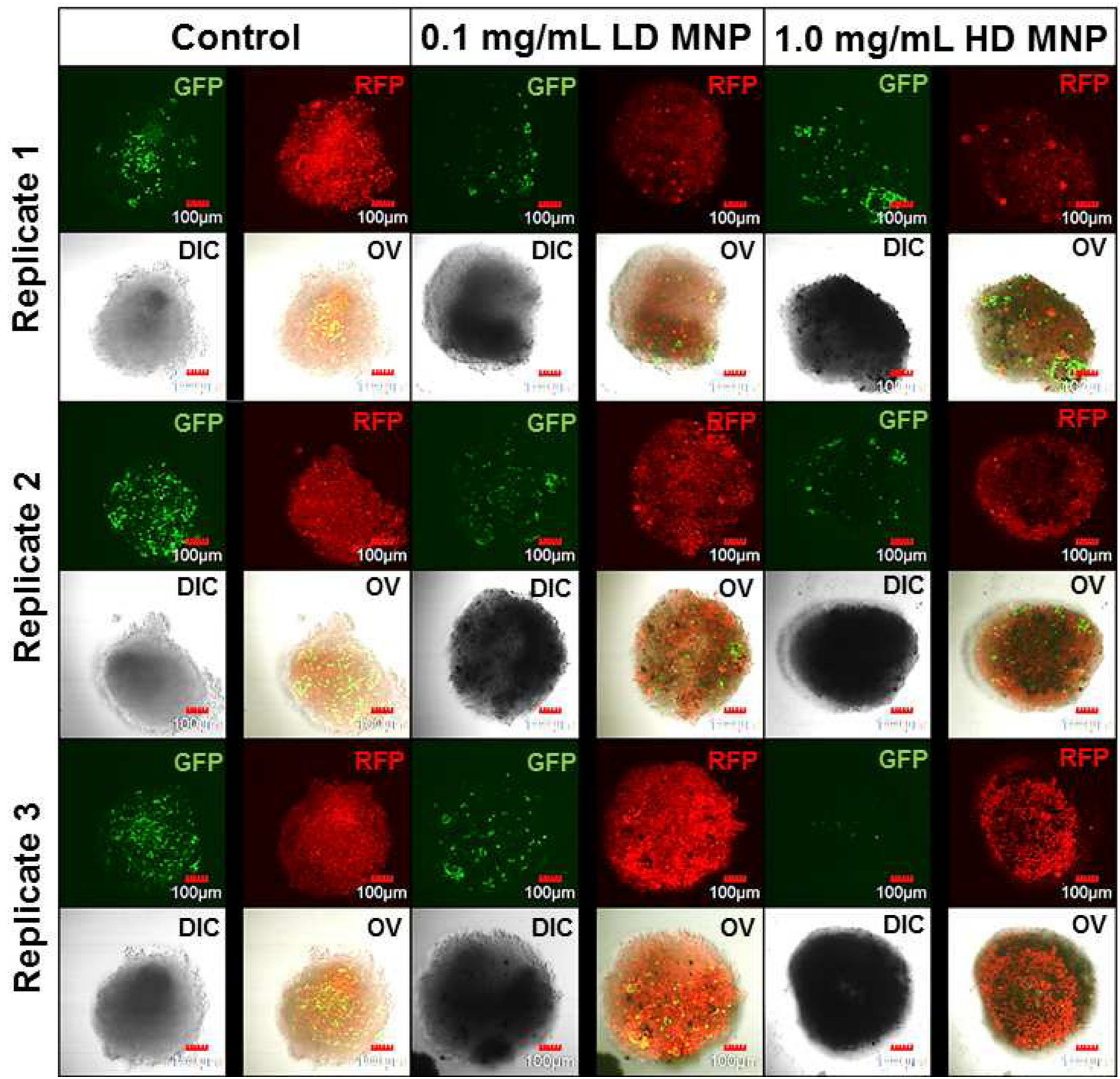

Figure 1. MNP exposure masks the fluorescence of color coded cell types in the TTA

Confocal Microscopy and DIC images of TTA without and with $0.1 \mathrm{mg} / \mathrm{mL}$, low (LD) and 1 $\mathrm{mg} / \mathrm{mL}$, high (HD) dose of MNP exposure. The treatment groups are arranged in columns with increasing MNP dose from left to right. Each treatment group has 3 replicates. Each panel consists of the following 4 images: GFP: (green fluorescent protein-expressing C166 endothelial cells, top left), RFP: (red fluorescent protein-expressing 4T1 murine mammary carcinoma cells, top right), DIC: (differential interference contrast image, bottom left), and OV: (overlay of the images, bottom right). Images were capture day 5 post treatment. 


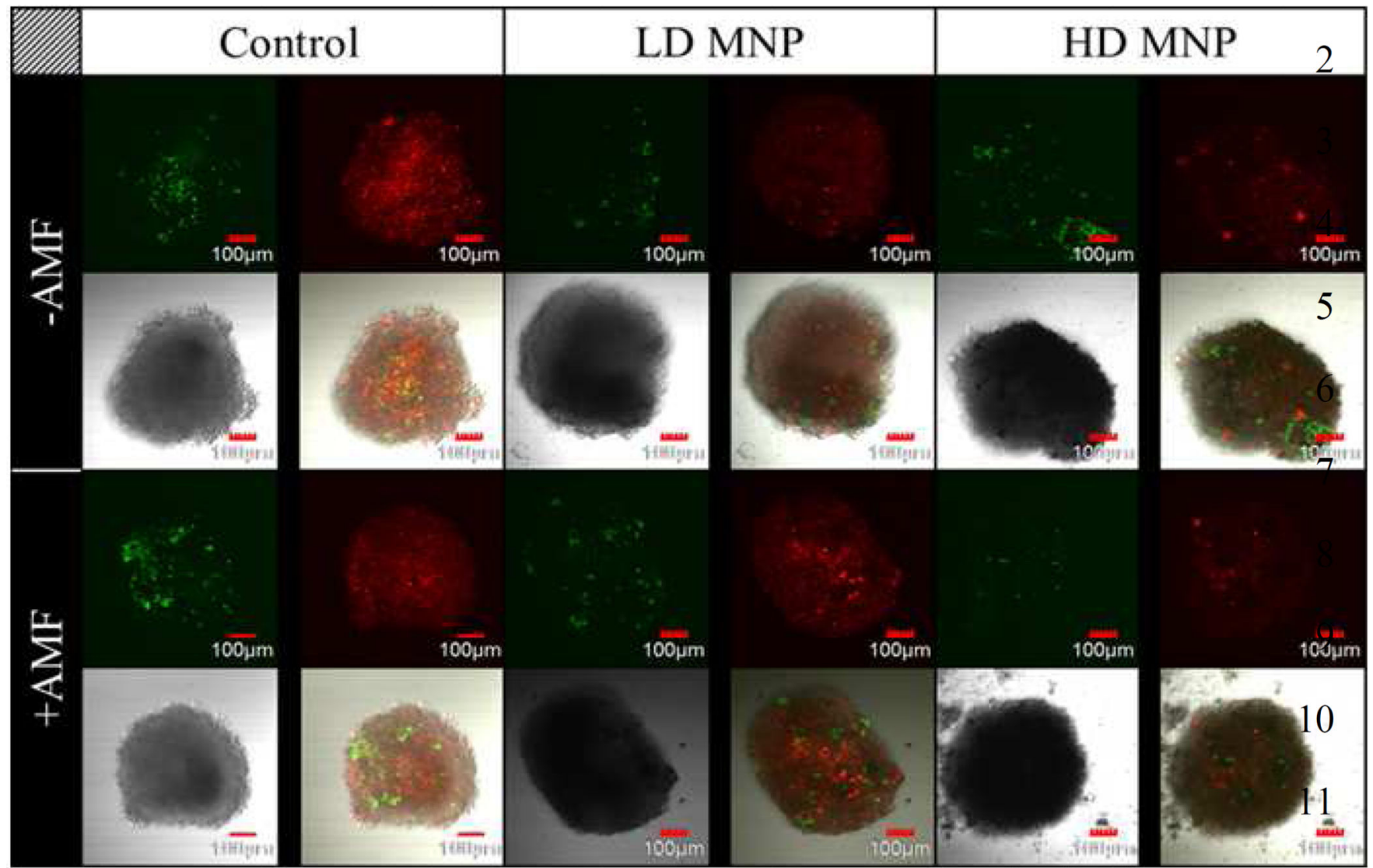

Figure 2. MNP exposure combined with Magnetic hyperthermia induced by AMF exposure causes release of cellular debris from TTA

Comparison of TTA with- (+AMF; bottom row) and without (-AMF; top row) application of AMF for 1-hour. The treatment groups are arranged in columns with increasing MNP dose from left to right. Each panel consists of the following 4 representative confocal images: green fluorescent (GFP-expressing C166 endothelial cells, top left), red fluorescent (RFP-expressing 4T1 murine mammary carcinoma cells, top right), DIC (bottom left), and overlay (bottom right). Images were captured at day 5 post MNP exposure. 

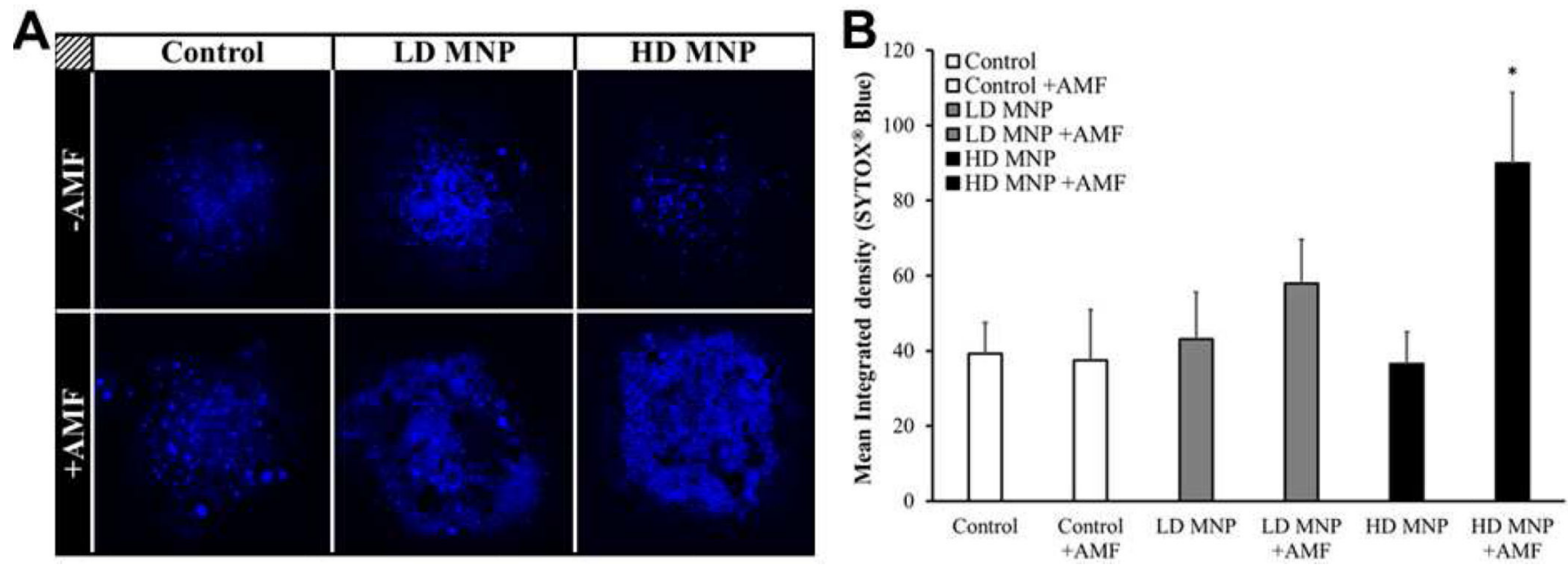

Figure 3. Increased cell damage in TTA resulting from MNP exposure and AMF induced magnetic hyperthermia

(A) Representative images of cell damage upon low dose $(0.1 \mathrm{mg} / \mathrm{mL})$ [LD] and high dose $(1 \mathrm{mg} / \mathrm{mL})$ [HD] treatment with and without AMF exposure as indicated by Sytox blue staining. (B) Toxicity of the MNP with and without magnetic hyperthermia induced by AMF exposure for $1 \mathrm{hr}$. was evaluated by quantification of dead cell count measured as the mean integrated density of blue signal of the Sytox blue staining from fluorescent images using an ImageJ software and graphically represented. ( $\mathrm{N}=5 \mathrm{TTA} / \mathrm{group},{ }^{*} \mathrm{p}<0.05$, for TTA exposed to HD MNP with AMF compared to all other treatment groups). 


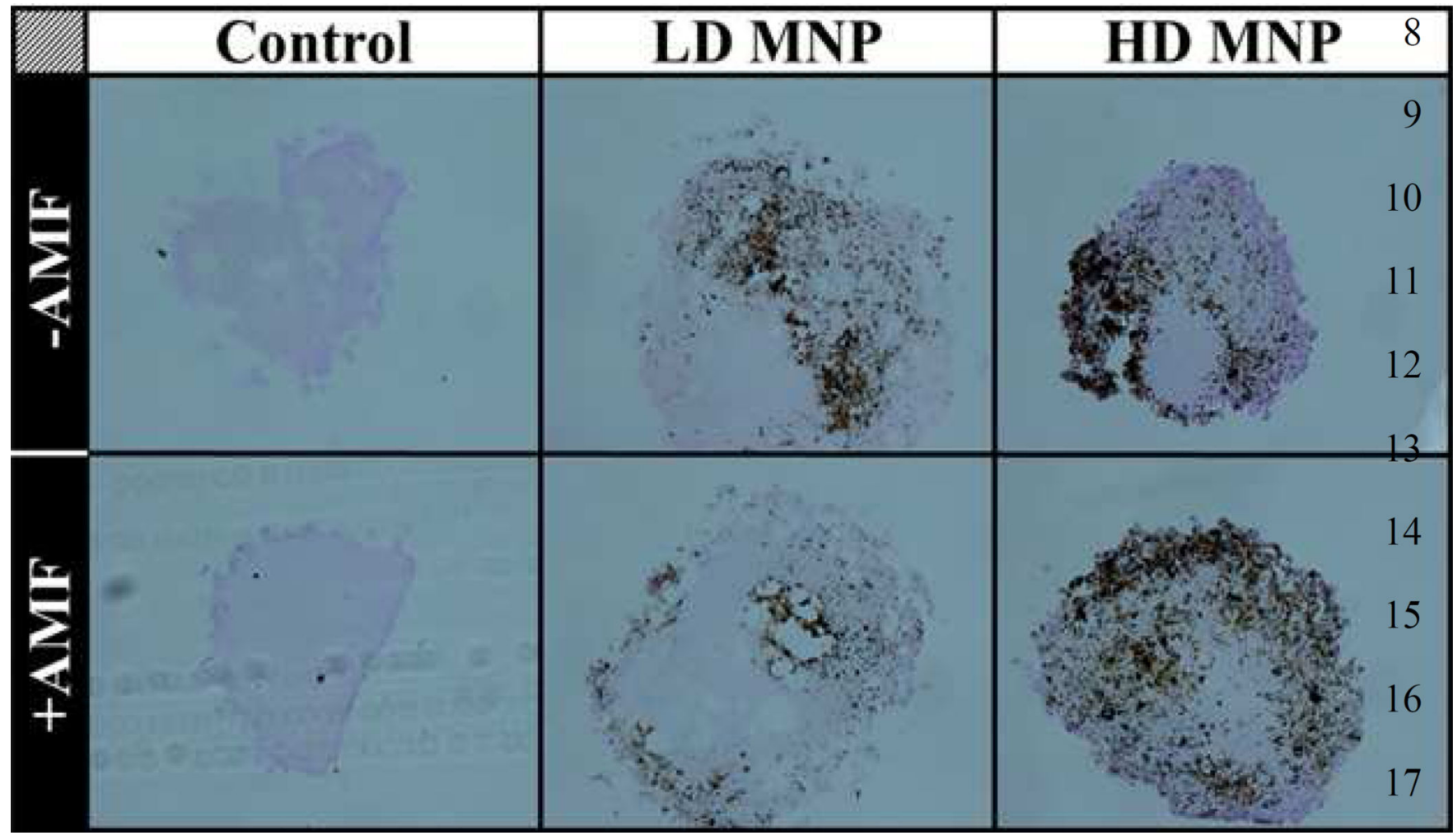

Figure 4. Higher accumulation of MNP in TTA with MNP exposure combined with AMF induced magnetic hyperthermia

Representative images of Prussian blue staining of microemetastatic TTA counterstained with nuclear fast red at $20 \times$ that were treated with low dose $(0.1 \mathrm{mg} / \mathrm{mL})$ [LD MNP] and high dose $(1 \mathrm{mg} / \mathrm{mL})$ [HD MNP] of MNP with and without exposure to magnetic hyperthermia induced by AMF for $1 \mathrm{hr}$. The untreated TTA [Control] served as control. 


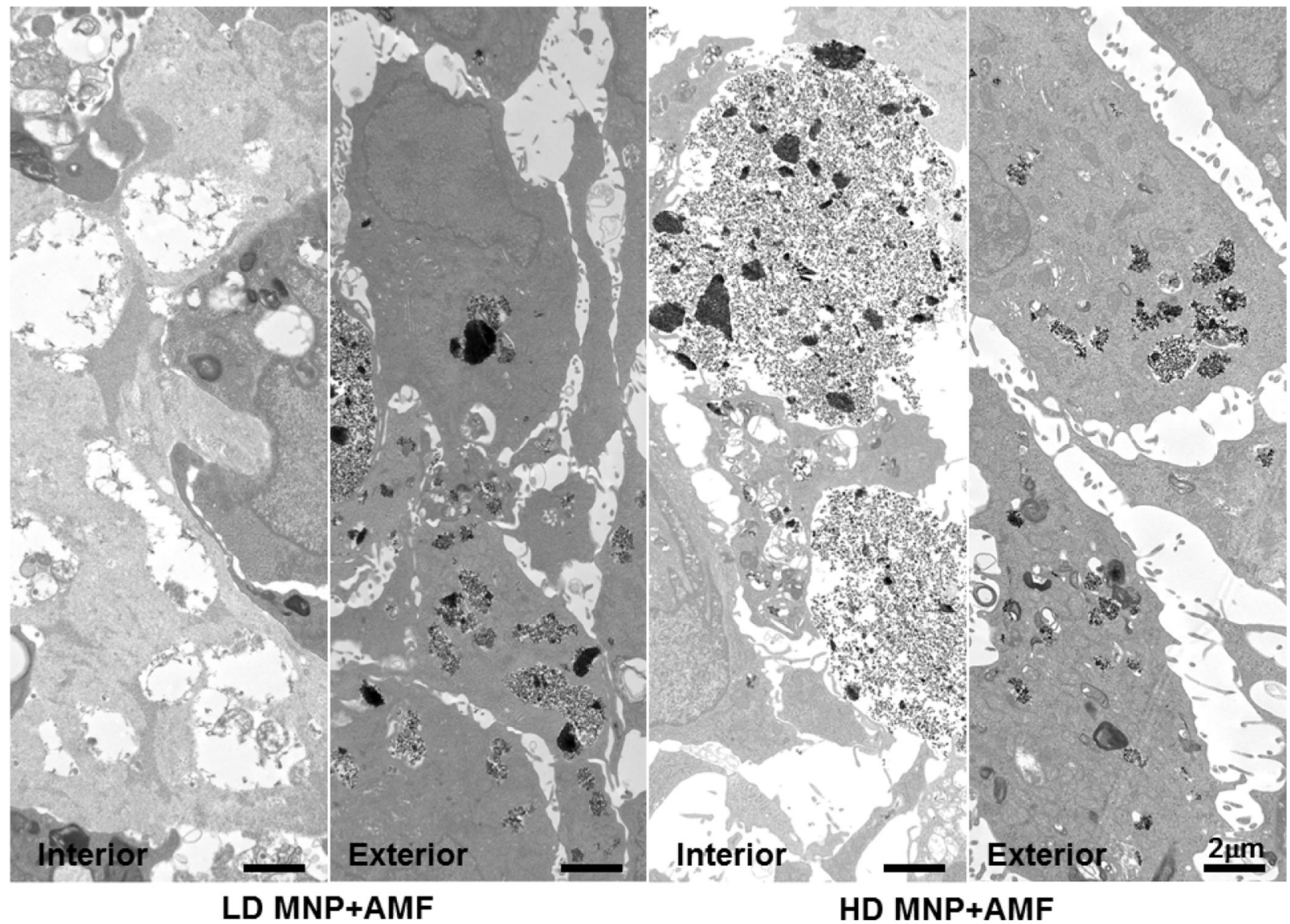

Figure 5. Representative TEM images demonstrating accumulation of MNP in the interior and exterior regions of the TTA 5 days post magnetic hyperthermia induced by remote actuation of the MNP upon low dose (LD, $0.1 \mathrm{mg} / \mathrm{mL})$ and high dose (,HD $1.0 \mathrm{mg} / \mathrm{mL})$ incubation with the TTA 

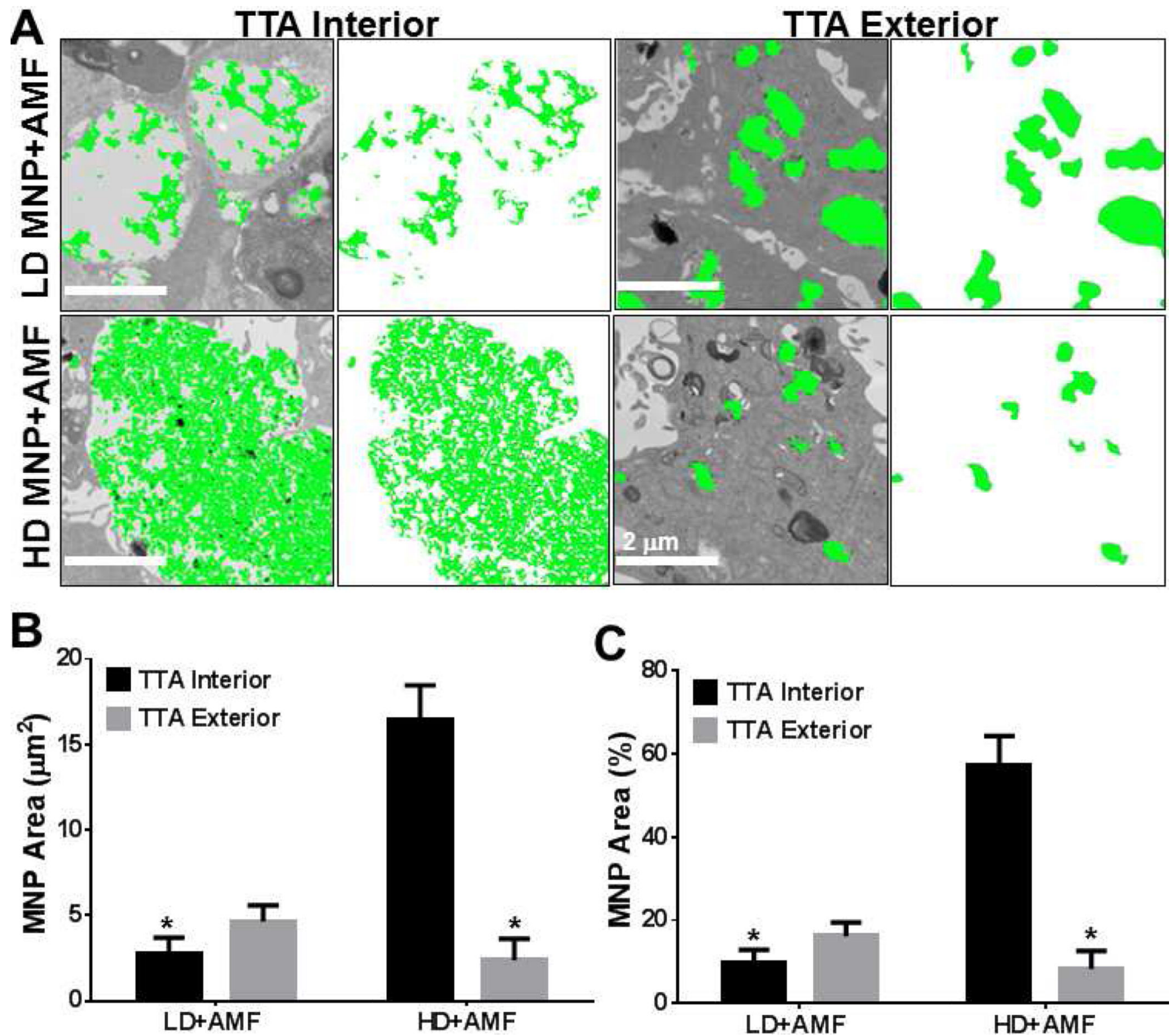

Figure 6. Quantitative analysis of MNP accumulation in the interior and exterior regions of TTA upon treatment with low and high dose of MNP with magnetic hyperthermia induced by AMF (A) Representative TEM images from the interior and exterior regions of the TTA post treatment as indicated in the figure that were manually colored for nanoparticle aggregation and processed using Adobe Photoshop CS6. The area of the extracted colored region was analyzed and quantitated using the ImageJ software. The data obtained was graphically represented as MNP area (B) and MNP percentage (C). N= 3 TTA/group, $*$ p $<0.05$, for TTA interior exposed to HD MNP with AMF compared to TTA interior with LD+AMF and TTA exterior with HD+AMF treatment. 


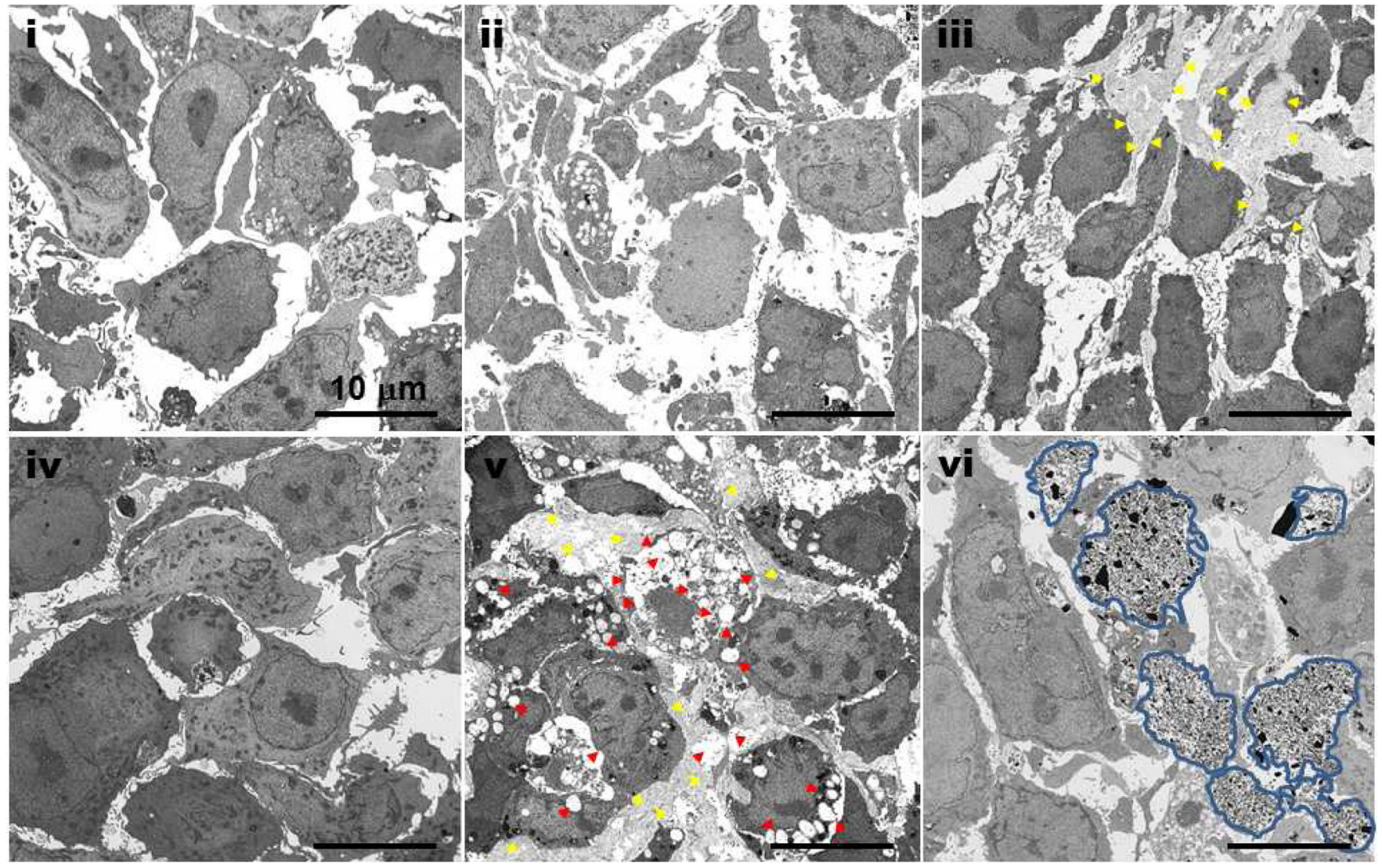

Figure 7. Increased nanoparticle accumulation or massive vacuolization and deposition of extracellular material upon MNP exposure with magnetic hyperthermia in TTA

(A) Representative TEM images from the center of the TTA showing nanoparticle accumulation (Blue outline), vacuolization (red arrows) and extracellular deposition (yellow arrows) when subjected to the following treatments: (i) Control-AMF; (ii) LD-AMF; (iii) HD-AMF; (iv) Control+AMF; (v) LD+AMF; (vi) HD+AMF. Scale bar: $10 \mu \mathrm{m}$. 


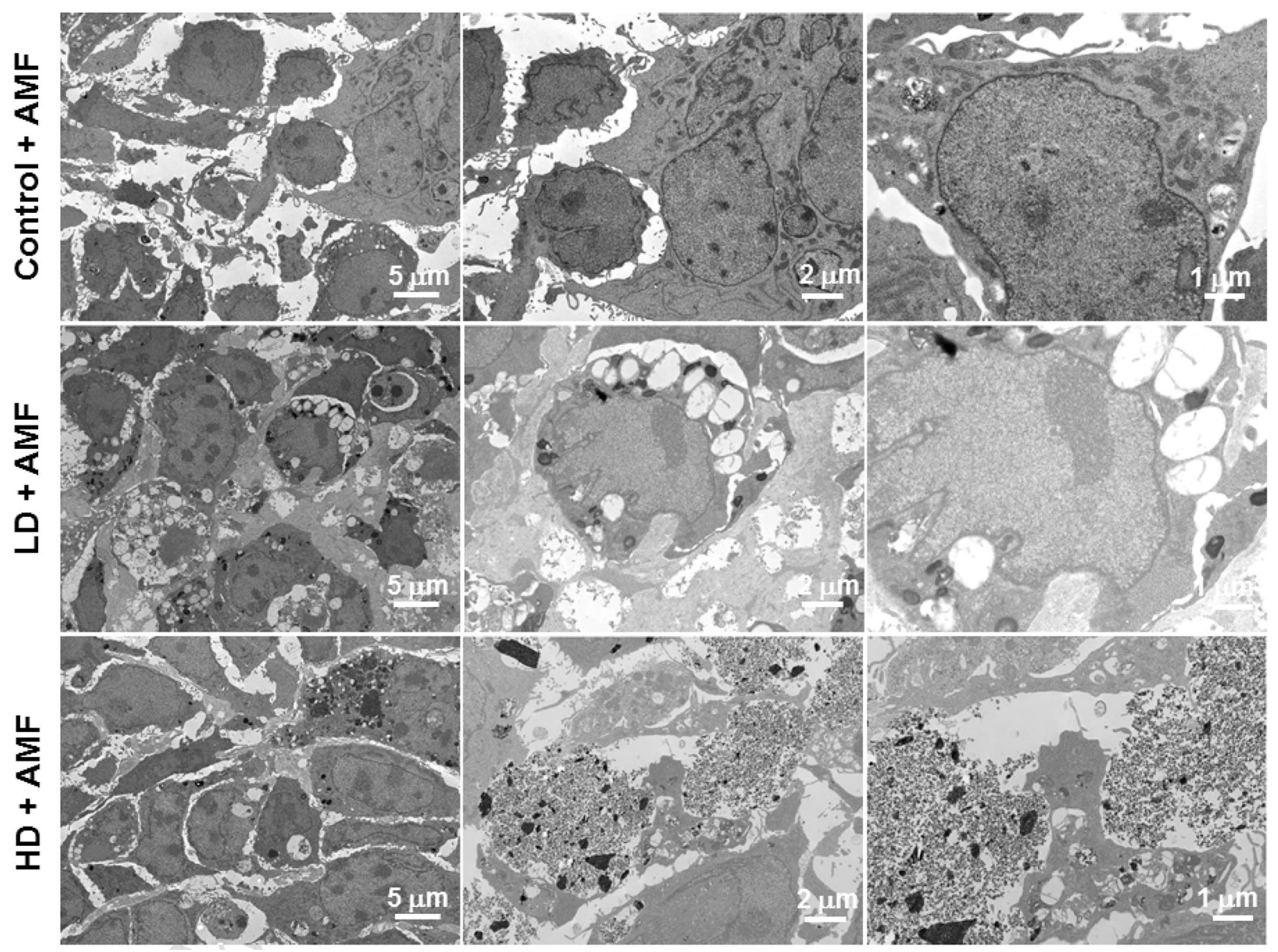

Figure 8. Representative TEM images from the center of the TTA with increasing magnification revealing aggregation of MNPs in the either in vacuoles and cells exposed to magnetic hyperthermia induced via remote actuation of low and high dose of MNP exposure using an AMF for $1 \mathrm{hr}$ respectively

TTA subject to AMF only [Control] served as control. Scale bar: 5, 2 and $1 \mu \mathrm{m}$. 

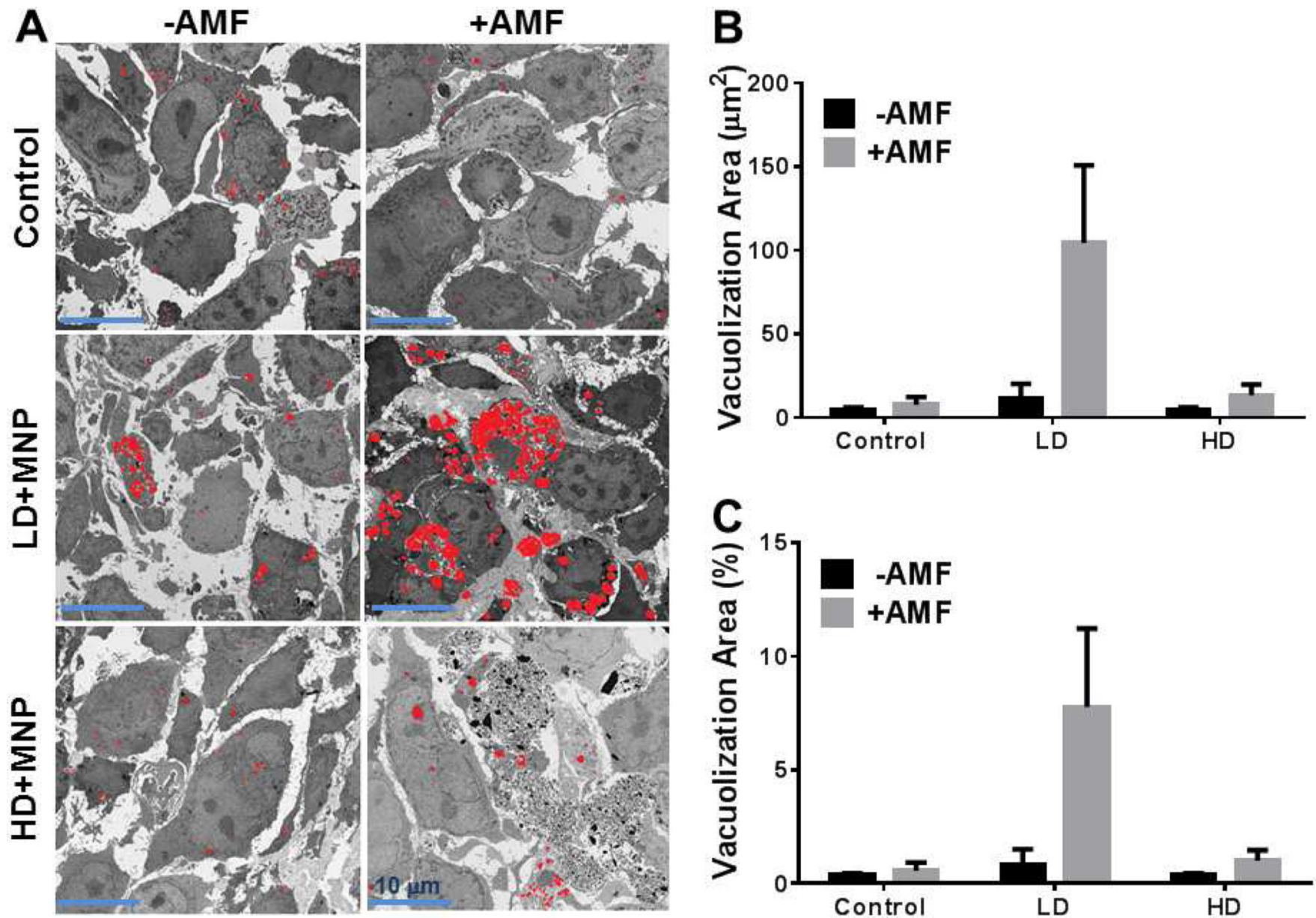

Figure 9. Quantitative analysis of vacuolization of the cytoplasm in TTA post treatment

(A) Representative TEM images that were manually colored for vacuolization and processed using Adobe Photoshop CS6. The area of the extracted colored region was analyzed and quantitated using the ImageJ software. The data obtained was graphically represented as vacuolization area (B) and vacuolization percentage (C). N= 3 TTA/group, *p $<0.05$, for TTA exposed to low dose MNP with AMF compared to high dose and control with AMF. 


\section{Table 1}

BCM tumor tissue analogs (5 BCM microtissues/petridish with replicates each) were randomized into six treatment groups as summarized.

\begin{tabular}{|l|l|l|l|}
\hline System & $\begin{array}{l}{[\mathbf{M N P}]} \\
(\mathbf{m g} / \mathbf{m L})\end{array}$ & $\begin{array}{l}\text { MNP exposure } \\
\text { time (hours) }\end{array}$ & $\begin{array}{l}\text { AMF exposure } \\
\text { time (hours) }\end{array}$ \\
\hline Control & - & 24 & $\mathbf{0}$ \\
\hline LD MNP & 0.1 & 24 & $\mathbf{0}$ \\
\hline HD MNP & 1.0 & 24 & $\mathbf{0}$ \\
\hline Control + AMF & - & 24 & $\mathbf{1}$ \\
\hline LD + AMF & 0.1 & 24 & $\mathbf{1}$ \\
\hline HD + AMF & 1.0 & 24 & $\mathbf{1}$ \\
\hline
\end{tabular}

